Article

\title{
Scrophularia buergeriana Extract Improves Memory Impairment via Inhibition of the Apoptosis Pathway in the Mouse Hippocampus
}

\author{
Hae Jin Lee ${ }^{1}$, Dae Young Lee ${ }^{2} \mathbb{1}$, Hae Lim Kim ${ }^{1}$ and Seung Hwan Yang ${ }^{1, * \mathbb{C}}$ \\ 1 Department of Biotechnology, Chonnam National University, Yeosu 59626, Korea; haecutejin@naver.com (H.J.L.); \\ ics1357@naver.com (H.L.K.) \\ 2 Department of Herbal Crop Research, National Institute of Horticultural and Herbal Science, RDA, \\ Eumsung 27709, Korea; dylee0809@korea.kr \\ * Correspondence: ymichigan@jnu.ac.kr; Tel.: +82-61-659-7306
}

Received: 23 October 2020; Accepted: 9 November 2020; Published: 11 November 2020

\begin{abstract}
Scrophularia buergeriana (SB) Miq. (Scrophulariaceae) has been used to help cure swelling and fever and has reported antioxidant and neuro-protective effects. However, few mechanism-based studies have evaluated the memory-improving effects in a beta-amyloid induced memory loss model. As a result of Scrophularia buergeriana extract (SBE) administration (30 and $100 \mathrm{mg} / \mathrm{kg}$ ) for 28 days significantly recovered beta-amyloid-induced amnesia in the passive avoidance test and improved the impairment of spatial memory in the Morris Water Maze (MWM) task. Furthermore, SBE up-regulated superoxide dismutase-1 (SOD)-1, SOD-2, glutathione peroxidase-1, and B-cell lymphoma (Bcl)-2 protein expression levels. Additionally, SBE downregulated Bcl-2-associated X protein, cleaved caspase-9, cleaved poly (adenosine diphosphate-ribose) polymerase, and A $\beta$ protein expression levels and inhibited the phosphorylation of the tau protein of $A \beta$-treated mice hippocampus. These results demonstrate that SBE improved memory impairment by reducing beta-amyloid induced neurotoxicity and regulated oxidative stress, anti-apoptotic pathways.
\end{abstract}

Keywords: srophularia buergeriana; cognitive impairment; amyloid beta; tau phosphorylation; oxidative stress; anti-apoptotic

\section{Introduction}

Alzheimer's disease (AD) is one type of dementia and a progressive neuro-degenerative disease featured by deposits of extracellular amyloid $\beta(\mathrm{A} \beta)$ peptide and flame-shaped neurofibrillary tangles of hyper-phosphorylated tau protein, inducing neurotoxicity accompanied by cognitive impairment and memory loss [1-4].

The $A \beta$ plaque is composed of $A \beta 1-40$ and 1-42, major forms of $A \beta$ found in the brains of $A D$ patients. The $A \beta 1-42$ protein is more neurotoxic and induces more oxidative damage than $A \beta 1-40$ [5]. An important factor in AD development is considered to be $\mathrm{A} \beta$ accumulation, since oxidative stress is followed by $A \beta$ cytotoxicity $[1,6]$. The overproduction of reactive oxygen species (ROS) induced $\mathrm{A} \beta$ accumulation and oxidative stress damages cellular components resulting in structural damage, functional disorder, and cell apoptosis [7].

Cells have an antioxidant defense system protecting them from ROS attacks using various enzymes, such as superoxide dismutase (SOD), glutathione peroxidases (GPx), glutathione reductases (GR) [8]. SOD is known as the first detoxification enzyme and the most powerful endogenous antioxidant in the cell. It acts as a catalyst and converse of the superoxide $\left(\mathrm{O}^{2-}\right)$ radical into ordinary oxygen $\left(\mathrm{O}^{2}\right)$ and hydrogen peroxide $\left(\mathrm{H}_{2} \mathrm{O}_{2}\right)$, leaving the harmful superoxide anion less dangerous. 
SOD requires a metal cofactor, such as copper $(\mathrm{Cu})$, zinc $(\mathrm{Zn})$ and manganese $(\mathrm{Mn})$, for activity as a metalloenzyme [9]. $\mathrm{Cu} / \mathrm{Zn}-\mathrm{SOD}$ (SOD1), which is located in chromosome 21 and encoded in the SOD1 gene located on chromosome 21 and predominantly occurs in the cytosolic compartment. Mn-SOD (SOD2), which is located in chromosome 6 and encoded in the SOD2 gene on chromosome 6, located in the mitochondrial matrix. The reduction of SOD-1 triggers oxidative cellular DNA damage, and SOD-2 protects mitochondrial DNA against damage due to oxidative stress [10]. GPx plays an import role in protecting cells from oxidative damage by converting hydrogen peroxide $\left(\mathrm{H}_{2} \mathrm{O}_{2}\right)$ to $\mathrm{H}_{2} \mathrm{O}$ with glutathione (GSH) as a substrate, after the oxidation of GSH to Glutathione disulfide (GSSG). GR is known to maintain the reduced GSH level in redox cycle. Furthermore, it resists oxidative stress and maintains a reducing environment inside the cell $[11,12]$.

In addition, $A \beta$-mediated oxidative stress causes the hyper-phosphorylation of tau protein and affects neurofibrillary tangle formation. The accumulation of neurofibrillary tangles directly correlates with neuro-degeneration and cell death and is closely related to the severity of dementia $[13,14]$.

Apoptosis is mediated by two major pathways, which are divided into extrinsic and intrinsic pathways. Death receptors release several mitochondrial intermembrane proteins by passing death signaling to mitochondria in the intrinsic pathway [15]. A common mitochondria-related apoptotic pathway in neurons is regulated principally by the pro-apoptotic Bcl-2 protein family member, Bax. On receipt of the death signal, Bax is translocated to the mitochondria and interacts with the Bcl-2 family to control the progression of apoptosis $[16,17]$. Bax activates down-stream effector caspases such as caspase- 9 and caspase-poly (ADP) ribose polymerase (PARP) in vitro, and in vivo by stimulating cytochrome c release. Notably, Bcl-2 inhibits Bax-induced apoptosis [15,18,19].

Scrophularia buergeriana (SB) Miq. (Scrophulariaceae), called Hyun-Sam in Korea, is used to help cure fever, swelling, constipation, pharyngitis, neuritis, and laryngitis as traditional medicine. SB dried root contains various components such as E-harpagoside (CAS: 19210-12-9), 8-O-E-p-methoxycinnamoyl harpagide (MCA-Hg), E-p-methoxycinnamic acid (p-MCA, CAS: 830-09-1), cinnamic acid (CAS: 140-10-3), and angoroside C (CAS: 115909-22-3), which displays neuro protective activities [11]. In a previous study, the SB extract (SBE) demonstrated cognition-enhancing activity in a scopolamine-induced short-term memory loss mice model [12]. However, investigation evaluating the effects of SBE in a beta-amyloid induced memory loss model is lacking.

Therefore, we administrated 30 or $100 \mathrm{mg} / \mathrm{kg}$ SBE based on the previous study and evaluated the effect of SBE on $\beta$-amyloid accumulation and tau phosphorylation. Furthermore, we investigated the neuro-protective effects against $A \beta$ caused neurotoxicity through antioxidant and anti-apoptotic mechanisms in the $A \beta 1-42$ injected mice.

\section{Materials and Methods}

\subsection{Sample Preparation}

SBE was obtained from Nutrapharmtec co., Ltd., (Seongnam, Korea). SB dried roots were extracted for $2-4 \mathrm{~h}$ at $70-90{ }^{\circ} \mathrm{C}$ with $70 \%$ ethyl alcohol and filter processed, concentrated, and dried. The extraction process was performed with reference to previously described studies [11,12]. For the in vivo study, the standardized SBE was dissolved in $0.5 \%$ carboxy-methylcellulose (CMC).

\subsection{Experimental Animals}

Male C57BL/6N mice ( 8 weeks old; Orient. Co. Ltd., Gyeonggi, Korea) were used after 7 days adaptation period $\left(20-26{ }^{\circ} \mathrm{C}\right.$; $12 \mathrm{~h}$ light cycle from 08:00 to 20:00; food, Doo Yeol Biotech, water ad libitum). All studies were conducted according to the animal experiment ethical committee (permission number: 2018-07-008) of ChemOn Inc (Yong in, Korea). The animals were cared based on the guidelines provided by this committee. We monitored changes in body weight, food and water intake once a week. To enhance the well-being of the animals, we provided hygienic and ensured proper breeding and care to prevent disease. 


\subsection{A 1-42 Injection and Drug Administration}

The experimental animals were grouped as follows: normal control group, $A \beta 1-42$ treated group, and co-treated groups with A $\beta 1-42$ and the SBE (30 or $100 \mathrm{mg} / \mathrm{kg} /$ day). SBE was dissolved in $0.5 \%$ CMC and orally administered for 4 weeks (Day 28). The passive avoidance test and Morris water maze (MWM) were performed for 3 (Days 15-17) and 7 (Days 22-28) days. The A $\beta$ peptide was dissolved in sterile $0.1 \mathrm{M}$ phosphate-buffered saline (pH 7.4) and pre-incubated at $37^{\circ} \mathrm{C}$ for 7 days. Zoletil ${ }^{\circledR}$ (Virbac, Carros, France) and xylazine (Bayer, Leverkusen, Germany) $(4: 1, v / v)$ were used for mice to anesthetize and $A \beta$ 1-42 was injected ( $5 \mu \mathrm{L} / 2.5 \mathrm{~min}$, i.c.v.) using stereotax ic apparatus coordinates (Anterior/Posterior (AP), $-1.0 \mathrm{~mm}$; Mediolateral/Lateral (ML), $+1.0 \mathrm{~mm}$; Dorsal/Ventral (DV), $-2.5 \mathrm{~mm}$ ).

\subsection{Passive Avoidance Test}

The passive avoidance test equipment (Twin County Med Associates, Hudson, NY, USA) was used to perform passive avoidance experiments. This apparatus is divided into light and dark compartments with a guillotine door in the middle. The bottom is gridded to administer an electric shock. The tests were carried out for 3 days at the same time every day at $24 \mathrm{~h}$ intervals. For adaptation training, the animals were placed in the shaded area for $2 \mathrm{~min}$, and then placed back in the illuminated area. When the animal moved into the shaded area, it was immediately placed in the illuminated compartment (day 15). Twenty-four hours later (day 16), two training sessions were performed every $2 \mathrm{~min}$. After $60 \mathrm{~s}$ of adaptation, the animals were allowed to move between the two compartments freely for $120 \mathrm{~s}$. However, on moving to the shaded area, the guillotine door was closed and a $0.20 \mathrm{~mA}$ scrambled shock was applied for $2 \mathrm{~s}$. The animals that failed to move were excluded from and 8 mice per group participated in the experiments. On the last day of testing, (day 17), the animal was located on the illuminated area and the guillotine door was opened. The time taken to move to the shaded area was measured.

\subsection{Morris Water Maze (MWM) Test}

The MWM test was performed 22 days after the A $\beta$ 1-42 peptide injection. The platform was placed in one of the four designated release points in the water pool, allowing the animal a search time of $60 \mathrm{~s}$. The mice that found the platform were left on it for $30 \mathrm{~s}$, but the mice that failed to find the platform within $60 \mathrm{~s}$ were placed on the platform and allowed to rest for about $30 \mathrm{~s}$. All mice tested twice a day, and the position of the platform was randomly changed in the water pool. Using this method, we measured the time taken to locate the platform by repeating the test for 7 consecutive days (training: 2 days, behavioral test: 4 days, probe trial: 1 day). On the last 7 days (Day 28), a probe trial was conducted. Here, $1 \mathrm{~h}$ after vehicle or drug administration, the platform was taken out of the pool, and the number of times the mice passed the platform was measured for $60 \mathrm{~s}$ on Day 28. The entire experiment plan is exhibited in Figure 1.

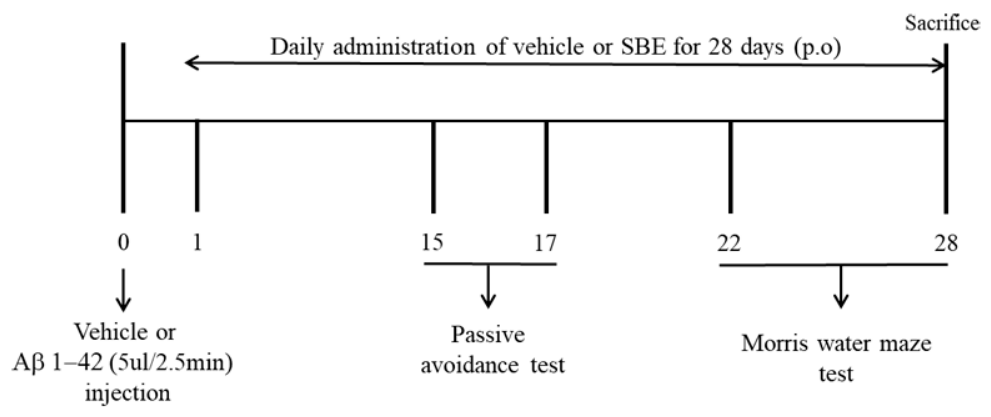

Figure 1. Experimental plan of this study. 


\subsection{Preparation of Tissue Samples}

The mice were anesthetized and sacrificed after behavioral tasks for biochemical studies. The hippocampus was separated from the brain tissue and then immediately stored at $-80{ }^{\circ} \mathrm{C}$ until further assessment.

\subsection{Glutathione Reductase (GR) Activity}

GR enzyme activity was determined using the Glutathione Reductase Assay Kit (Abcam, Cambridge, UK). Hippocampal tissues were homogenized in cold assay buffer, and centrifuged at $10,000 \times \mathrm{g}$ for $15 \mathrm{~min}$ at $4{ }^{\circ} \mathrm{C}$. The separated supernatant from hippocampus was taken and kept at $-80^{\circ} \mathrm{C}$ until further analysis. This assay is based on the reduction of glutathione by nicotinamide adenine dinucleotide phosphate (NADP)H in the presence of GR. GR activity can be detected by measuring the change in absorbance at $405 \mathrm{~nm}$.

\subsection{Western Blotting}

Hippocampal tissues were homogenized with RIPA buffer and 1\% protease inhibitor cocktail (Roche, Mannheim, Germany) and the lysate was centrifuged at $10,000 \times g$ for $15 \min$ at $4{ }^{\circ} \mathrm{C}$. The separated supernatant from hippocampus was taken, and protein concentrations were measured using a BCA protein assay kit (Thermo, Waltham, MA, USA). The proteins were separated using $8 \%$ or $12 \%$ SDS-PAGE and were then moved to polyvinylidene difluoride membranes (Millipore Corp., Bedford, MA, USA). The membranes were initially incubated to block with 5\% non-fat skimmed milk in Tris-buffered saline containing 0.1\% Tween-20 for $30 \mathrm{~min}$. Next, they were incubated with specific primary antibodies against SOD-1, SOD-2, GPx-1, A $\beta$ (1:1000; Santa Cruz Biotechnology, Santa Cruz, CA, USA), Bax, Bcl-2, cleaved Caspase-9, cleaved PARP, phospho-tau, tau, and $\beta$-actin (1:1000; Cell Signaling Technology, Inc., Danvers, MA, USA) for $1 \mathrm{~h}$ at $23{ }^{\circ} \mathrm{C}$. The membranes were then incubated in the corresponding horseradish peroxidase-conjugated anti-rabbit, anti-mouse immunoglobulin G (1:10000; GenDEPOT, Barker, TX, USA) for $1 \mathrm{~h}$ at $23{ }^{\circ} \mathrm{C}$. The membrane was detected using the ECL system (Atto, Tokyo, Japan). The intensity of the bands on the membrane was detected by Image-Pro Plus software (6.0 Version; Media Cybernetics, Silver Spring, MD, USA)

\subsection{Statistical Analysis}

The experimental results are expressed as standard error of the mean (SEM) and were assessed using the SPSS program (version 22.0, SPSS Inc., Chicago, IL, USA). Difference value of between treatment groups were analyzed by Student's $t$-test and one-way analysis of variance (ANOVA), and performed following multiple comparisons correction using Dunnett's post-hoc test using Origin 7.0 software (OriginLab, Northampton, MA, USA). $p<0.05$ indicates that there is a statistical difference, and $p<0.01$ was considered statistically highly significant between mean values.

\section{Results}

\subsection{Effects of the Scrophularia Buergeriana Extract (SBE) on the Passive Avoidance Test in A $\beta$ 1-42 Treated Mice}

To determine the effect of SBE on memory deficits, we conducted the passive avoidance test in the $\mathrm{A} \beta$-induced mouse model. A $\beta$-injected mice demonstrated a remarkable reduction in the time to move from the illuminated compartment to the shaded area compared to normal mice $(p<0.01)$, implying that the learning capacity was lowered. However, the step-through latency was dose-dependently increased in mice administered with SBE $30 \mathrm{mg} / \mathrm{kg}(p<0.05)$ and $100 \mathrm{mg} / \mathrm{kg}(p<0.01)$ (Figure 2) compared to A $\beta$-injected mice. 


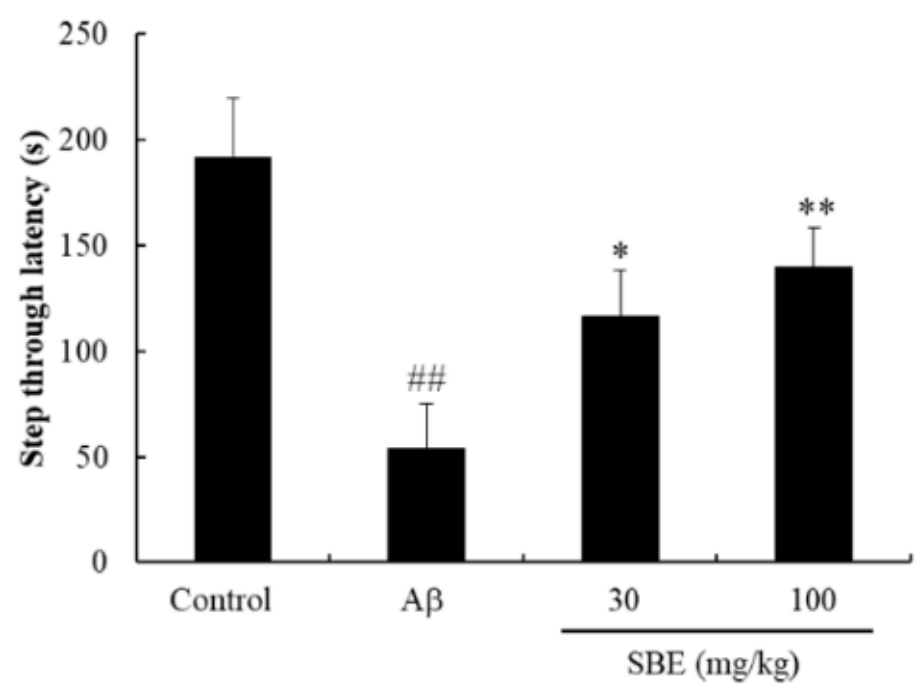

Figure 2. Effects of Scrophularia buergeriana extract (SBE) on the step-through latency of passive avoidance performance in $\mathrm{A} \beta 1-42$ treated mice. The data are expressed as means \pm standard error of the mean (SEM) of independent experiments $(n=8)$. \#\# $p<0.01$ vs. Control group; ${ }^{*} p<0.05$ and ${ }^{* *} p<0.01$ vs. $\mathrm{A} \beta(1-42)$ group.

\subsection{Effects of the SBE on the MWM Test in Aß 1-42 Induced Memory Deficit Mice}

To investigate the memory-enhancing effect of SBE, we next performed the MWM test in C57BL/6 mice. Normal mice quickly located the platform during four consecutive behavioral tests. The $A \beta$-injected group exhibited a significantly delayed escape latency compared to the normal group from days 25-27. However, mice treated with SBE $30 \mathrm{mg} / \mathrm{kg}$ and $100 \mathrm{mg} / \mathrm{kg}$ demonstrated a shortened escape latency from days 25-27 (Figure 3A). Furthermore, we observed that A $\beta$-injected mice demonstrated significantly increased swim distances to find the platform compared to the normal control mice (Figure 3B). We confirmed that SBE $30 \mathrm{mg} / \mathrm{kg}(p<0.05)$ and $100 \mathrm{mg} / \mathrm{kg}(p<0.01)$ on day 27 decreased the distance traveled to locate the platform. In the probe trials (Figure $3 \mathrm{C}$ ), the $\mathrm{A} \beta$-treated mice reported a decreased number of crossings over the previous platform position against as the control mice. The number of crossings was recovered by treatment with SBE $30 \mathrm{mg} / \mathrm{kg}(p<0.05)$ and $100 \mathrm{mg} / \mathrm{kg}(p<0.01)$ compared to the $\mathrm{A} \beta$-injected mice and the recovery was significant. Therefore, we confirmed that SBE enhanced spatial recognition in the MWM test.

\subsection{Effects of the SBE on Glutathione Reductase (GR) Activity in the Hippocampus}

To evaluate the effects of SBE on GR activity of $A \beta$ treatment mice, GR activity was measured in the hippocampal tissue. GR activity was significantly reduced in mice treated with $A \beta$ compared with the normal group. However, mice treated with SBE $30 \mathrm{mg} / \mathrm{kg}(p<0.05)$ and $100 \mathrm{mg} / \mathrm{kg}(p<0.05)$ significantly increased hippocampal GR activity compared to the A $\beta$-treated group. Furthermore, the efficacy of SBE was comparable to the normal group mice (Figure 4). 
A
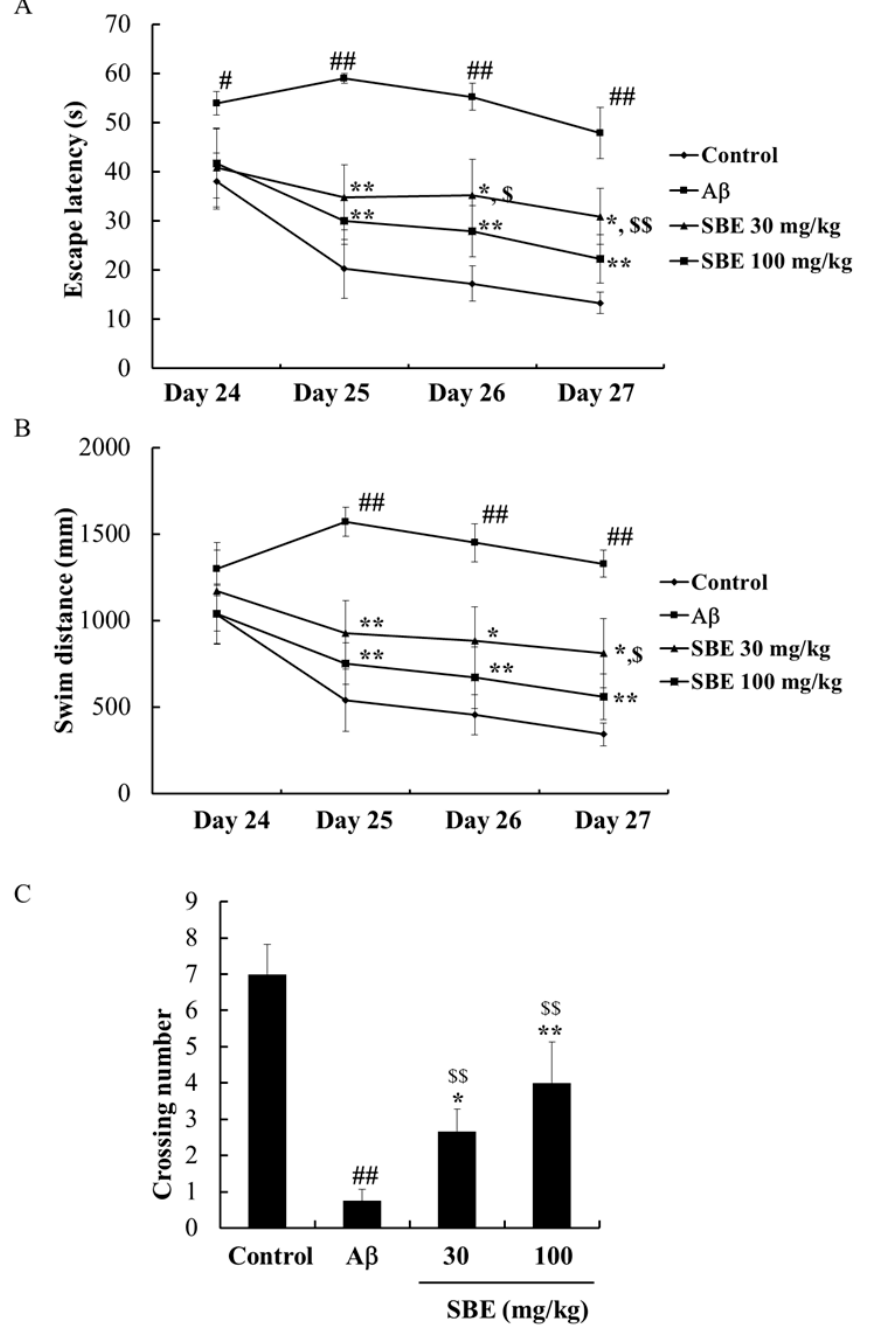

Figure 3. Effects of SBE on A $\beta$ 1-42 induced memory impairment in the Morris water maze (MWM). (A) The escape latency and (B) Swim distance was recorded across 4 days (Day 24-Day 27). (C) The number of crossings in a probe trial performed on Day 28. The data are expressed as means \pm SEM of independent experiments $(n=8)$. \# $p<0.05$ and \#\# $p<0.01$ vs. Control group; $\$<0.05$ and $\$ \$<0.01$ vs. Control group; ${ }^{*} p<0.05$ and ${ }^{* *} p<0.01$ vs. $\mathrm{A} \beta(1-42)$ group.

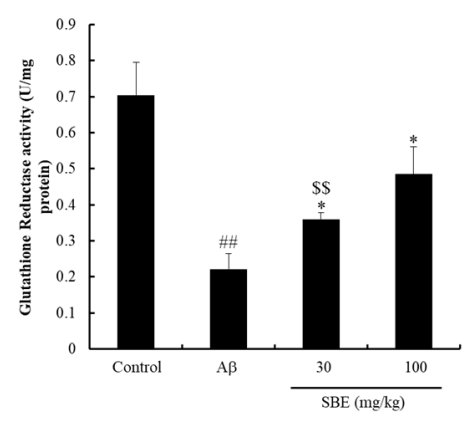

Figure 4. Effects of SBE on glutathione reductase (GR) activity in the mouse hippocampus. The hippocampus was lysed, and the supernatant was used to measurement GR activity. The results were calculated as a unit of nicotinamide adenine dinucleotide phosphate (NADPH) oxidized per protein and expressed as means \pm SEM of independent experiments $(n=3)$. \#\# $p<0.01 \mathrm{vs.} \mathrm{Control}$ group; $\$ \$<.01$ vs. Control group; ${ }^{*} p<0.05$ vs. $A \beta(1-42)$ group. 


\subsection{Effects of the SBE on the Antioxidant Enzymes in Hippocampus of A $1-42$ Treated Mice}

To investigate the effects of SBE on antioxidant enzymes in the hippocampus of $A \beta$ treated mice, the protein levels of SOD1, SOD2, and GPx-1 were evaluated. The protein levels of SOD1, SOD2, and GPx-1 were markedly decreased in mice treated with $A \beta$ against the control group. Furthermore, treatment with SBE $30 \mathrm{mg} / \mathrm{kg}$ increased GPx-1 protein expression by 1.3-fold. In addition, SOD1, SOD2, and GPx-1 protein levels were further increased in mice administered SBE $100 \mathrm{mg} / \mathrm{kg}$ by $4.2-, 1.7-$ and 2.9-fold, respectively, compared to the A $\beta$-treated group (Figure 5).
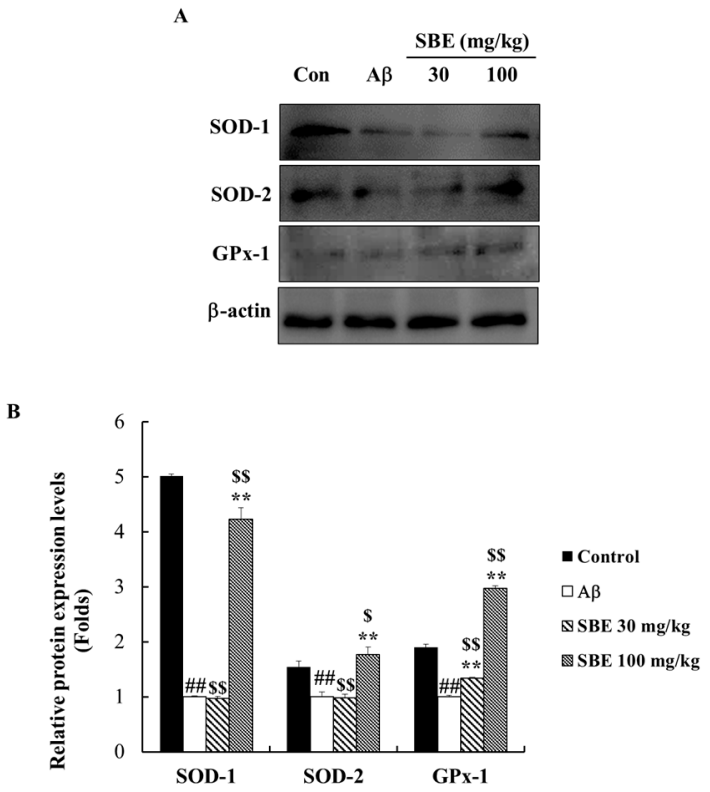

Figure 5. Effects of SBE on antioxidant protein expression levels in the hippocampus of memory-impaired mice. (A) The expression of superoxide dismutase 1 (SOD1), SOD2, and glutathione peroxidase-1 (GPx-1) were detected by Western blotting analysis. (B) The protein bands were quantified and calculated using the relevant software. Protein expression levels were normalized on $\beta$-actin level. The data are expressed as means \pm SEM of independent experiments $(n=3)$. \#\# $p<0.01$ vs. Control group; $\$<0.05$ and $\$ \$<0.01$ vs. Control group; ${ }^{* *} p<0.01$ vs. $\mathrm{A} \beta(1-42)$ group.

\subsection{Effects of the SBE on Apoptosis in the Hippocampus of Aß 1-42 Treated Mice}

To demonstrate the protective effect of SBE on A $\beta$-induced apoptosis, the protein expression levels of Bax, Bcl-2, caspase-9, and cleaved PARP were analyzed in the hippocampal tissue. A $\beta$ treatment significantly increased the protein levels of Bax, cleaved Caspase-9, and cleaved PARP. Conversely, the $\mathrm{Bcl}-2$ protein levels decreased in the $\mathrm{A} \beta$-treated group. Bcl-2/Bax are known as important proteins related to apoptosis in the mitochondria. The Bax protein level was dose-dependently reduced with SBE treatment by $31 \%$ and $51 \%$, and SBE $100 \mathrm{mg} / \mathrm{kg}(p<0.01)$ significantly increased the levels of $\mathrm{Bcl}-2$ and Bcl-2/Bax by 1.41- and 2.87-fold, respectively, compared to the A $\beta$-treated group in Figure 6 . SBE $30 \mathrm{mg} / \mathrm{kg}$ and $100 \mathrm{mg} / \mathrm{kg}$ significantly reduced the levels of cleaved caspase- 9 by $61 \%$, and $76 \%$, respectively, and reduced cleaved PARP by $33 \%$ and, $74 \%$, respectively, compared to the A $\beta$ treatment group. Therefore, we confirmed that SBE exhibited a prominent neuro-protective effect. 
A

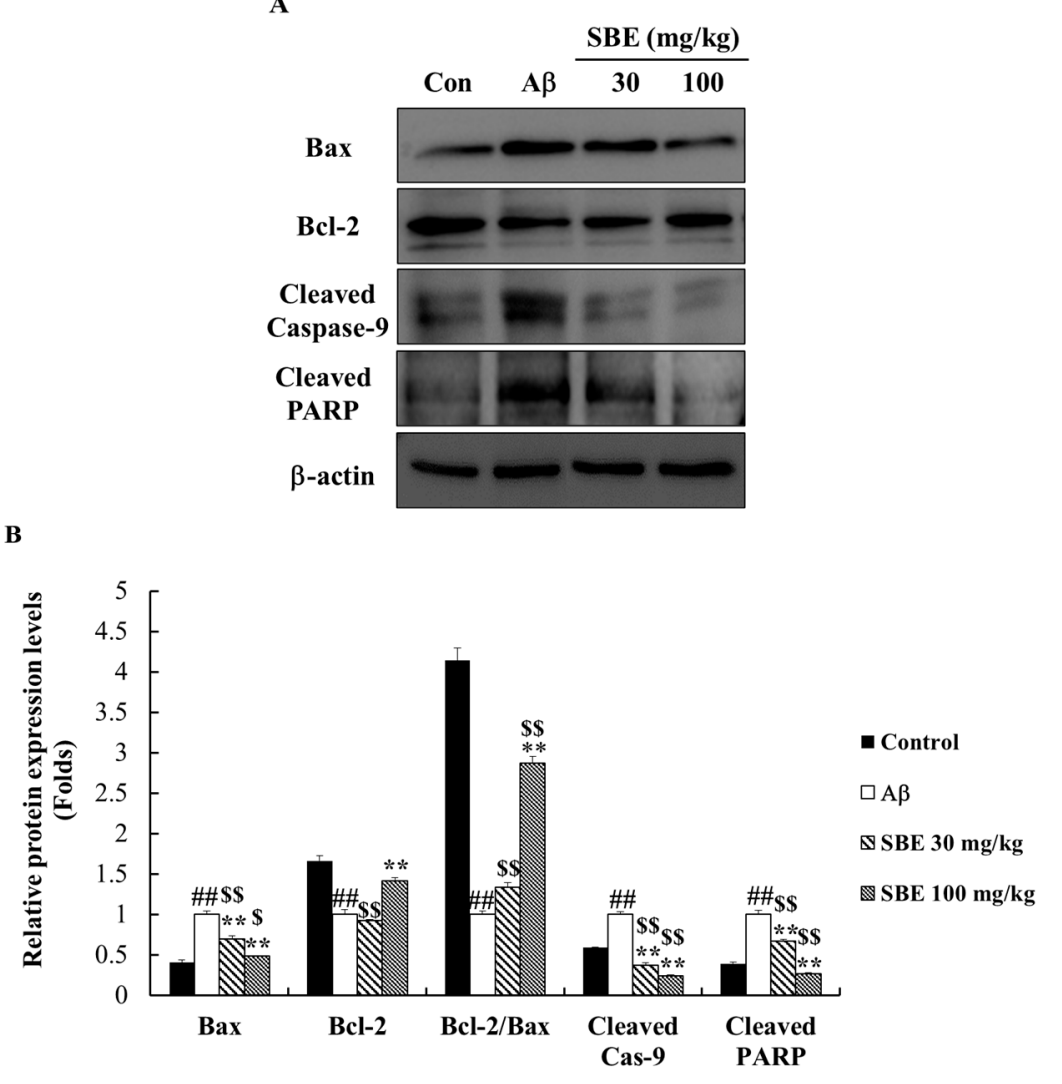

B

Figure 6. Effects of SBE on apoptotic protein expression levels in the hippocampus of memory-impaired mice. (A) The expression of Bcl-2-associated X protein (Bax), B-cell lymphoma 2 (Bcl-2), cleaved caspase-9 and cleaved poly (adenosine diphosphate (ADP)-ribose) polymerase (PARP) was detected by Western blotting analysis. (B) The protein bands were quantified and calculated using the software. Protein expression levels were normalized on $\beta$-actin level. The data are expressed as means \pm SEM of independent experiments $(n=3)$. \#\# $p<0.01$ vs. Control group; $\$<0.05$ and $\$ \$<0.01$ vs. Control group; ${ }^{* *} p<0.01$ vs. A $\beta(1-42)$ group.

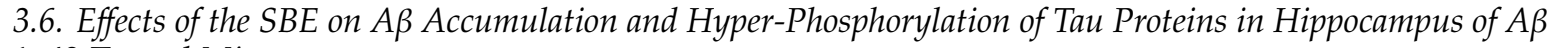
1-42 Treated Mice

The pathological hallmarks of $\mathrm{AD}$ include $\mathrm{A} \beta$ accumulation and tau hyper-phosphorylation. The hyper-phosphorylation of the tau protein, can contribute to neuronal degeneration. Using western blot analysis, we confirmed that the $\mathrm{A} \beta$ injection promoted $\mathrm{A} \beta$ accumulation in the mouse hippocampus (Figure 7). The administration of SBE $30 \mathrm{mg} / \mathrm{kg}(p<0.01)$ and $100 \mathrm{mg} / \mathrm{kg}(p<0.01)$ significantly reduced $A \beta$ accumulation in the hippocampus against as the $A \beta$ injection group by $22 \%$ and $53 \%$, respectively (Figure $7 B$ ). Based on the protective effect of SBE on $A \beta$ accumulation, we confirmed the effect of SBE on tau phosphorylation in $A \beta$ treated mice. $A \beta$ treatment increased the tau protein phosphorylation compared to the normal group, and treatment with SBE $30 \mathrm{mg} / \mathrm{kg}$ and $100 \mathrm{mg} / \mathrm{kg}$ significantly attenuated $A \beta$ induced hyper-phosphorylation of tau by $69 \%$ and $71 \%$, respectively, compared to the $\mathrm{A} \beta$ treatment group. 
A
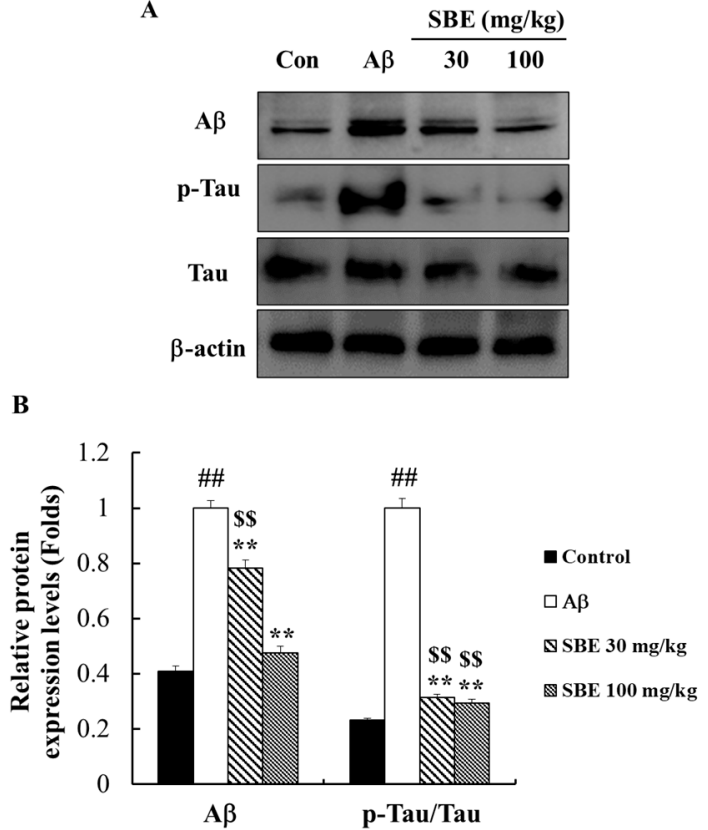

Figure 7. Effects of SBE on amyloid-beta protein expression levels and phosphorylation of tau protein levels in the hippocampus of memory-impaired mice. (A) The expression of amyloid-beta (A $\beta$ ) and phospho (p)-tau was detected by Western blotting analysis. (B) The protein bands were quantified and calculated using the software. Phosphorylation levels of the tau protein were normalized to those of tau, and $A \beta$ protein expression level was normalized on $\beta$-actin level. The data are expressed as means \pm SEM of independent experiments $(n=3)$. \#\# $p<0.01$ vs. Control group; $\$ \$<0.01$ vs. Control group; ${ }^{* *} p<0.01$ vs. A $\beta(1-42)$ group.

\section{Discussion}

Previously, we reported that SBE extracts demonstrate potent anti-amnesic activity and anti-apoptotic effects in a scopolamine-induced memory impairment mouse model and in the SH-SY5Y cell line $[11,12]$. In vitro studies have shown that SBE treatment inhibited cell death induced by glutamate. Furthermore, the in vivo study indicates that acute and prolonged treatment with SBE demonstrates the highest anti-oxidant activity in the scopolamine-induced memory impairment model. However, research on amyloid-beta, which affects in the development of AD, is insufficient. The first report aimed to identify the neuro-protective activities, including amyloid-beta accumulation prevention effects and related mechanisms of chronic SBE administration in the A $\beta$ 1-42-induced cognitive deficit mice model.

$\mathrm{AD}$ is a progressive, neurodegenerative disorder that causes damage to the brain and is characterized by cognitive decline, and irreversible memory loss. Amyloid-beta peptides, and hyper-phosphorylated tau protein comprising neurofibrillary tangles have been considered critical factors of pathological hallmarks of $\mathrm{AD}[10]$. Indeed, $\mathrm{A} \beta$ levels were higher in the brain of $\mathrm{AD}$ patients than normal aged brain samples, indicating clinical signs such as spatial memory loss [20,21].

To assess cognitive deficits, passive avoidance and MWM tasks were performed to investigate learning and memory skills. The passive avoidance task is used to confirm the memory function by measuring the escape time from the space. The MWM task is the most widely used laboratory behavioral test to assess hippocampal-dependent cognitive deficits and learning functions in mice and rats $[20,22,23]$. Injection of $A \beta 1-42$ resulted in severe cognitive impairments and memory loss in the passive avoidance test and MWM, as well as neurodegeneration. However, SBE treatment dose-dependently increased the step-through latency in the passive avoidance task and decreased escape latency and swim distance significantly for 4 days of MWM trials. This implied that SBE 
administration improves cognitive performance and ameliorates memory deficits, although not as completely as the normal model that did not cause memory loss.

In the previous study, we have demonstrated that neuronal cell death and cognitive deficiency due to oxidative stress are related to $A \beta$ accumulation in the brain. [24]. $A \beta$ is a known neuro-toxic peptide that promotes oxidative stress and lipid peroxidation in the intermembrane and also causes ROS generation by serving as a source of ROS $[5,6,25]$. The accumulation of $A \beta$ may result in an increased production of ROS, subsequently leading to neuronal death through apoptotic pathways [25,26]. To prevent ROS generation and regulate the steady-state $\mathrm{O}^{2}$ concentration, cells have anti-oxidant defense systems such as SODs, GR and GPx-1 enzymes [11,12,27]. A $\beta 1-42$ injection attenuated hippocampal antioxidant enzyme activities and protein expression levels, the same as in previous studies [28,29]. Nevertheless, we observed that the administration of SBE $(30,100 \mathrm{mg} / \mathrm{kg})$ could significantly enhance GR activity and SODs, GPx-1 protein levels in the A $\beta$ 1-42-treated mouse hippocampus.

The mitochondria are much more sensitive to oxidative stress and $A \beta$-mediated oxidative stress increased mitochondrial dysfunction leading to apoptotic cell death. The accumulated $A \beta$ triggers neuronal death in the hippocampus by releasing caspase activators $[24,29,30]$. A $\beta$-induced apoptosis is regulated by mediators such as caspases, Bcl-2, and Bax [10]. The proportion of Bax and Bcl-2 affects whether a cell undergoes or escapes apoptosis. The caspase pathway promotes apoptosis and releases apoptosis-promoting factors when the Bax/Bcl-2 ratio is increased [20]. In our study, SBE treatment significantly lowered Bax, cleaved caspase-9, and cleaved PARP protein expression levels and upregulated Bcl-2 protein expression levels at the same time in mice hippocampal tissue.

$A \beta$ injections increased the accumulation of $A \beta$ and induced hyper-phosphorylation of the tau protein in the brain. The brains of AD patients demonstrate abnormally phosphorylated tau, $4-8$-fold higher than normal brains [31]. In this study, the $A \beta$-injection increased the phosphorylated tau protein expression levels about 4-5 times as against the normal control. We observed that the $A \beta$ and phosphorylated tau protein expression levels dose-dependently decreased in response to treatment with SBE compared to the normal group.

However, this pre-clinical study has some limitations and we will confirm the anti-inflammatory effects of SBE in a mouse model induced neuroinflammation and memory loss in a further study. Further studies are also needed for immunohistochemical analysis and the effect of SBE in clinical trials.

Collectively, our results indicate that SBE treatment improved memory impairment through reduction of $A \beta$ accumulation and the regulation of oxidative stress, anti-apoptotic pathways, and tau protein hyper-phosphorylation in the A $\beta$ 1-42 memory impairment-induced hippocampal tissue.

\section{Conclusions}

This study demonstrated that SBE possesses antioxidant and neuroprotective effects against a $\beta$-amyloid induced memory loss model. Amyloid beta generates oxidative stress as an early event in $\mathrm{AD}$ and causes tau phosphorylation, mitochondria dysfunction and ROS generation. Consecutively, it leads to apoptosis and neurodegeneration. SBE treatment ameliorates memory deficits and improves learning and memory function. SBE also exhibited remarkable neuroprotective effects against $A \beta 1-42$ induced neurotoxicity via the apoptosis pathway (Figure 8). This study offers SBE at a dose of $100 \mathrm{mg} / \mathrm{kg}$ which suggests the possibility of development as a health functional food for the improvement of learning and memory impairment. 


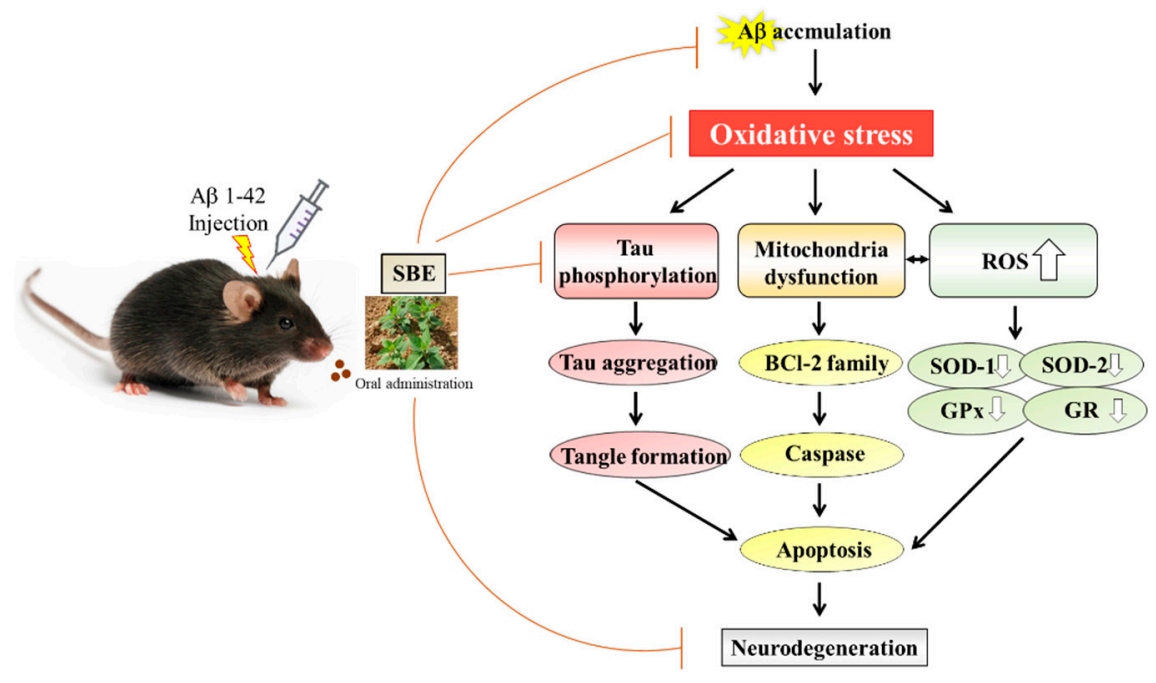

Figure 8. The proposed mechanism by which SBE ameliorates learning and memory in mice following an injection of amyloid- $\beta$ 1-42 (A $\beta$ 1-42).

Author Contributions: H.J.L. conducted the experiments and participated in the interpretation and writing of the manuscript. D.Y.L. and H.L.K. performed the data analysis and quality control assessment respectively. S.H.Y. planned and led the project, and contributed the data review, editing and manuscript finalization. All authors have read and agreed to the published version of the manuscript.

Funding: This study was carried out with the support of the 'Cooperative Research Program for Agriculture Science and Technology Development (Project no. PJ013215012020' Rural Development Administration, Republic of Korea.

Conflicts of Interest: The authors declare no conflict of interest in this study.

\section{References}

1. Wen, H.; Fu, Z.; Wei, Y.; Zhang, X.; Ma, L.; Gu, L.; Li, J. Antioxidant Activity and Neuroprotective Activity of Stilbenoids in Rat Primary Cortex Neurons via the PI3K/Akt Signaling Pathway. Molecules 2018, $23,2328$. [CrossRef] [PubMed]

2. Huang, D.S.; Yu, Y.C.; Wu, C.H.; Lin, J.Y. Protective Effects of Wogonin against Alzheimer's Disease by Inhibition of Amyloidogenic Pathway. Evid. Based Complement Alternat. Med. 2017, 3, 1-13. [CrossRef] [PubMed]

3. Paul Murphy, M.; LeVine, H. Alzheimer's Disease and the $\beta$-Amyloid Peptide. J. Alzheimers Dis. 2010, $19,311$. [CrossRef] [PubMed]

4. Huang, H.C.; Jiang, Z.F. Accumulated amyloid-beta peptide and hyperphosphorylated tua protein: Relationship and links in Alzheimer's disease. J. Alzhimers Dis. 2009, 16, 15-17. [CrossRef] [PubMed]

5. Klein, A.M.; Kowall, N.W.; Ferrante, R.J. Neurotoxicity and oxidative damage of beta amyloid 1-42 versus beta amyloid 1-40 in the mouse cerebral cortex. Ann. N. Y. Acad. Sci. 1999, 893, 314-320. [CrossRef]

6. Kim, D.H.; Jung, W.Y.; Park, S.J.; Kim, J.M.; Lee, S.; Kim, Y.C.; Ryu, J.H. Anti-amnesic effect of ESP-102 on A $\beta$ (1-42)-induced memory impairment in mice. Pharmacol. Biochem. Behav. 2010, 92, 239-248. [CrossRef]

7. Butterfield, D.A.; Reed, T.; Newman, S.F.; Sultana, R. Roles of amyloid $\beta$-peptide-associated oxidative stress and brain protein modifications in the pathogenesis of Alzheimer's disease and mild cognitive impairment. Free Radic. Biol. Med. 2007, 43, 658-677. [CrossRef]

8. Valle, V.; Oliver, J.; Roca, P. Role of uncoupling proteins in cancer. Cancers 2010, 2, 567-591. [CrossRef]

9. Ighodaro, O.M.; Akinloye, O.A. First line defence anti-oxidants-superoxide dismutase (SOD), catalase (CAT) and glutathione peroxidase (GPX): Their fundamental role in the entire antioxidant defence grid. Alex. J. Med. 2018, 54, 287-293. [CrossRef]

10. Suganthy, N.; Malar, D.S.; Devi, K.P. Rhizophora mucronata attenuates beta-amyloid induced cognitive dysfunction, oxidative stress and cholinergic deficit in Alzheimer's disease animal model. Metab. Brain Dis. 2016, 4, 937-949. [CrossRef] 
11. Lee, H.J.; Spandidos, D.A.; Tsatsakis, A.; Margina, D.; Izotov, B.N.; Yang, S.H. Neuroprotective effects of Scrophularia buergeriana extract against glutamate-induced toxicity in SH-SH5Y cells. Int. J. Mol. Med. 2019, 43, 2144-2152. [PubMed]

12. Jeong, E.J.; Ma, C.J.; Lee, K.Y.; Kim, S.H. KD-501, a standardized extract of Scrophulaira buergeriana has both cognitive-enhancing and antioxidant activities in mice given scopolamine. J. Ethnopharmacol. 2009, 121, 98-105. [CrossRef] [PubMed]

13. Liu, Z.; Li, P.; Wu, J.; Wang, Y.; Li, P.; Hou, X.; Zhang, Q.; Wei, N.; Zhao, Z.; Liang, H.; et al. The Cascade of Oxidative Stress and Tau Protein Autophagic Dysfunction in Alzheimer's Disease. In Alzheimer's Disease-Challenges for the Future; IntechOpen: London, UK, 2015; pp. 27-45. [CrossRef]

14. Brion, J.P. Neurofibrillary Tangles and Alzheimer's Disease. Eur. Neurol. 1998, 40, 130-140. [CrossRef] [PubMed]

15. Gu, Q.; Wang, J.D.; Xia, H.H.; Lin, M.C.; He, H.; Zou, B.; Tu, S.P.; Yang, Y.; Liu, X.G.; Lam, S.K.; et al. Activation of the caspase-8/Bid and Bax pathways in aspirin-induced apoptosis in gastric cancer. Carcinogenesis 2015, 26, 541-546. [CrossRef]

16. Selznick, L.A.; Zheng, T.S.; Flavell, R.A.; Rakic, P.; Roth, K.A. Amyloid beta-induced neuronal death is bax-dependent but caspase-independent. J. Neuropathol. Exp. Neurol. 2000, 59, 271-279. [CrossRef]

17. Westphal, D.; Dewson, G.; Czabotar, P.E.; Kluck, R.M. Molecular biology of Bax and Bak activation and action. Biochim. Biophys. Acta 2011, 1813, 521-531. [CrossRef]

18. Oltavai, Z.N.; Milliman, C.L.; Korsmeyer, S.J. Bcl-2 heterodimerizes in vivo with a conserved homolog, Bax, that accelerates programmed cell death. Cell 1993, 74, 609-619.

19. Finucane, D.M.; Boosy Wetzel, E.; Waterhouse, N.J.; Cotter, T.G.; Green, D.R. Bax-induced caspase activation and apoptosis via cytochrome c release from mitochondria is inhibitable by Bcl-xL. J. Biol. Chem. 1999, 274, 2225-2233. [CrossRef]

20. Lee, H.J.; Lee, S.K.; Lee, D.R.; Choi, B.K.; Le, B.; Yang, S.H. Ameliorating effect of Citrus aurantium and nobiletin on $\beta$-amyloid (1-42)-induced memory impairment in mice. Mol. Med. Rep. 2019, 20, 3448-3455. [CrossRef]

21. Zhu, H.; Yan, H.; Tang, N.; Li, X.; Pang, P.; Li, H.; Chen, W.; Guo, Y.; Shu, S.; Cai, Y.; et al. Impairment of spatial memory in an Alzheimer's disease model via degeneration of hippocampal cholinergic synapses. Nat. Commun. 2017, 22, 1676. [CrossRef]

22. Zhang, S.; Hu, X.; Guan, W.; Luan, L.; Li, B.; Tang, Q.; Fan, H. Isoflurane anesthesia promotes cognitive impairment by inducing expression of $\beta$-amyloid protein-related factors in the hippocampus of aged rats. PLOS ONE 2017, 12, e0175654. [CrossRef] [PubMed]

23. Tucker, L.B.; Velosky, A.G.; McCabe, J.T. Applications of the Morris water maze in translational traumatic brain injury research. Neurosci. Biobehav. Rev. 2018, 88, 187-800. [CrossRef] [PubMed]

24. Laniski, F.R.; Alves, C.B.; Souza, A.C.; Pinto, S.; Roman, S.S.; Rhoden, C.R.; Alves, M.P.; Luchese, C. Protective effect of meloxicam-loaded nanocapsules against amyloid- $\beta$ peptide-induced damage in mice. Behav. Brain Res. 2012, 230, 100-107. [CrossRef] [PubMed]

25. Butterfield, D.A.; Swomely, A.M.; Sultana, R. Amyloid $\beta$-peptide (1-42)-induced oxidative stress in Alzheimer disease: Importance in disease pathogenesis and progression. Antioxid. Redox Signal. 2013, 19, 823-835. [CrossRef] [PubMed]

26. Ganguly, G.; Chakrabarti, S.; Chatterjee, U.; Saso, L. Proteinpathy, oxidative stress and mitochondrial dysfunction: Cross talk in Alzheimer's disease and Parkinson's disease. Drug Des. Devel. Ther. 2017, 11, 797-810. [CrossRef]

27. Huang, W.J.; Zhang, X.; Chen, W.W. Role of oxidative stress in Alzheimer's disease (Review). Biomed. Rep. 2016, 4, 519-522. [CrossRef]

28. Resende, R.; Moreira, P.I.; Proenca, T.; Deshpande, A.; Busciglio, J.; Pereira, C.; Oliveria, C.R. Brain oxidative stress in a triple-transgenic mouse model of Alzheimer disease. Free Radic. Biol. Med. 2008, 15, $2051-2057$. [CrossRef]

29. Farajdokht, F.; Amani, M.; Mizaei Bravil, F.; Alihemmati, A.; Mohaddes, G.; Babri, S. Troxerutin protects hippocampal neurons against amyloid beta-induced oxidative stress and apoptosis. EXCEL J. 2017, 16, 1081-1089. 
30. Razaul, H.; Sarder, N.U.; Amir, H. Amyloid beta $(\mathrm{A} \beta)$ and Oxidative stress: Progression of Alzheimer's Disease. Adv. Biotech. Micro. 2018, 11,7-16. [CrossRef]

31. Iqbal, K.; Liu, F.; Gong, C.X.; Alonso Adel, C.; Grundke-lqbal, I. Mechanisms of tau-induced neurodegeneration. Acta Neuropathol. 2009, 118, 53-69. [CrossRef]

Publisher's Note: MDPI stays neutral with regard to jurisdictional claims in published maps and institutional affiliations.

(C) 2020 by the authors. Licensee MDPI, Basel, Switzerland. This article is an open access article distributed under the terms and conditions of the Creative Commons Attribution (CC BY) license (http://creativecommons.org/licenses/by/4.0/). 